\title{
BMJ open Life-event stress induced by the Great East Japan Earthquake was associated with relapse in ulcerative colitis but not Crohn's disease: a retrospective cohort study
}

\author{
Hisashi Shiga, ${ }^{1}$ Teruko Miyazawa, ${ }^{1}$ Yoshitaka Kinouchi, ${ }^{1}$ Seiichi Takahashi, ${ }^{1}$ \\ Gen Tominaga, ${ }^{2}$ Hiroki Takahashi, ${ }^{3}$ Sho Takagi, ${ }^{4}$ Nobuya Obana, ${ }^{5}$ Tatsuya Kikuchi, ${ }^{6}$ \\ Shinya Oomori, ${ }^{7}$ Eiki Nomura, ${ }^{8}$ Manabu Shiraki, ${ }^{9}$ Yuichirou Sato, ${ }^{5}$ \\ Shuichiro Takahashi, ${ }^{10}$ Ken Umemura, ${ }^{11}$ Hiroshi Yokoyama, ${ }^{12}$ Katsuya Endo, ${ }^{1}$ \\ Yoichi Kakuta, ${ }^{1}$ Hiroki Aizawa, ${ }^{13}$ Masaki Matsuura, ${ }^{2}$ Tomoya Kimura, ${ }^{9}$ \\ Masatake Kuroha, ${ }^{9}$ Tooru Shimosegawa ${ }^{1}$
}

To cite: Shiga H, Miyazawa T, Kinouchi Y, et al. Life-event stress induced by the Great East Japan Earthquake was associated with relapse in ulcerative colitis but not Crohn's disease: a retrospective cohort study. BMJ Open 2013;3:e002294. doi:10.1136/bmjopen-2012002294

- Prepublication history for this paper are available online. To view these files please visit the journal online (http://dx.doi.org/10.1136/ bmjopen-2012-002294).

Received 1 November 2012 Revised 29 December 2012 Accepted 9 January 2013

This final article is available for use under the terms of the Creative Commons Attribution Non-Commercial 2.0 Licence; see http://bmjopen.bmj.com

For numbered affiliations see end of article.

\section{Correspondence to} Dr Hisashi Shiga; shiga@med.tohoku.ac.jp

\section{ABSTRACT}

Objective: Stress is thought to be one of the triggers of relapses in patients with inflammatory bowel disease (IBD). We examined the rate of relapse in IBD patients before and after the Great East Japan Earthquake.

Design: A retrospective cohort study.

Settings: 13 hospitals in Japan.

Participants: 546 ulcerative colitis (UC) and 357 Crohn's disease (CD) patients who received outpatient and inpatient care at 13 hospitals located in the area that were seriously damaged by the earthquake. Data on patient's clinical characteristics, disease activity and deleterious effects of the earthquake were obtained from questionnaires and hospital records.

Primary outcome: We evaluated the relapse rate (from inactive to active) across two consecutive months before and two consecutive months after the earthquake. In this study, we defined 'active' as conditions with a partial Mayo score $=2$ or more (UC) or a Harvey-Bradshaw index $=6$ or more (CD).

Results: Among the UC patients, disease was active in 167 patients and inactive in 379 patients before the earthquake. After the earthquake, the activity scores increased significantly $(p<0.0001)$. A total of 86 patients relapsed (relapse rate $=15.8 \%$ ). The relapse rate was about twice that of the corresponding period in the previous year. Among the CD patients, 86 patients had active disease and 271 had inactive disease before the earthquake. After the earthquake, the activity indices changed little. A total of 25 patients experienced a relapse (relapse rate $=7 \%$ ). The relapse rate did not differ from that of the corresponding period in the previous year. Multivariate analyses revealed that UC, changes in dietary oral intake and anxiety about family finances were associated with the relapse.

Conclusions: Life-event stress induced by the Great East Japan Earthquake was associated with relapse in UC but not $C D$.

\section{ARTICLE SUMMARY}

\section{Article focus}

- Stress is thought to be one of the triggers of relapses in patients with inflammatory bowel disease (IBD); however, it would be unethical to impose stressful circumstances on IBD patients in order to examine their effects.

- Disease onset or aggravation of cardiovascular disease, respiratory disease, peptic ulcer, etc was reported to increase after the huge earthquake; however, there has been no report about relapses of IBD associated with the huge earthquake.

Key messages

- We examined the rate of relapse in IBD patients before and after a huge earthquake, the Great East Japan Earthquake of 11 March 2011 in Japan.

- Life-event stress induced by the earthquake was associated with relapse of ulcerative colitis (UC) but not Crohn's disease.

- This report suggests that we should take into account stress in the management of patients with IBD, especially those with UC.

Strengths and limitations of this study

- This is the first report that investigated the activities of a large number of IBD patients before and after a huge earthquake.

- We did not use validated scores that would objectively assess psychological stress, because it would be impossible to investigate stress several times before and after a devastating earthquake, given the usually unpredictable nature of earthquakes.

- Our study cannot exclude recall bias. 


\section{INTRODUCTION}

Inflammatory bowel disease (IBD) is a chronic remitting/ relapsing disease. Although no variable has been proven to be a trigger of relapses in patients with IBD, stress has been described as one possibility. ${ }^{1-8}$ On the other hand, some reports did not prove a relationship between psychological stress and exacerbations of IBD. ${ }^{9-11}$ A prospective or well-established case-controlled study should be undertaken to determine whether stress is actually related to relapses of IBD; however, it would be unethical to impose stressful circumstances on IBD patients in order to examine their effects.

On 11 March 2011, Japan was hit by one of the most powerful earthquakes in recorded history, the Great East Japan Earthquake. The disaster left more than 28000 people dead or missing, caused great damage or hardship in daily life, and also caused profound stress for all of the people, even those who did not suffer individual losses. It was surely one of the most stressful life events and might have contributed to relapses in IBD patients. In terms of earthquake-associated disease onset or aggravation, cardiovascular disease, respiratory disease, diabetes mellitus, hypertension and peptic ulcer were reported to have increased after the huge earthquake. ${ }^{12-17}$ However, there has been no report about relapses of IBD caused by the huge earthquake.

In this study, we examined the activities of IBD patients before and after the Great East Japan Earthquake, and evaluated their relapse and remission rates. We also aimed to identify factors that were related to relapse or remission of IBD.

\section{MATERIALS AND METHODS}

\section{Study subjects}

Thirteen hospitals (Tohoku University Hospital, Japanese Red Cross Ishinomaki Hospital, Sendai Medical Center, Takagi Clinic, Osaki Citizen Hospital, Sendai City Hospital, Japanese Red Cross Sendai Hospital, Miyagi Cancer Center, South Miyagi Medical Center and Kesennuma City Hospital in the Miyagi Prefecture; Iwate Prefectural Isawa Hospital, Iwate Prefectural Chubu Hospital, Iwate Prefectural Iwai Hospital in the Iwate Prefecture) participated in this study. These hospitals are located in the area that was seriously damaged by the Great East Japan Earthquake. We sent a total of 1080 questionnaires to ulcerative colitis (UC) and Crohn's disease (CD) patients who received care in these hospitals. Then we examined the hospital records for data on the patients who returned the questionnaires. Hospital data contained information such as gender, age, IBD duration, disease extent (total colitis, left-sided colitis and proctitis in UC), disease location (small intestine, colon and both small intestine and colon in CD), extraintestinal complications, use of medications, smoking status and pregnancy experience. Written informed consent was obtained from all participants under the protocol approved by the Tohoku University Hospital Committee for Clinical Investigation.

To evaluate the degree of stress objectively, we also obtained data about each patient's situation regarding the earthquake, such as damage to the patient's house, duration of homelessness, deaths of family members or friends, changes in daily dietary intake, discontinuation or delay in taking medications, loss of job, family finances and changes in smoking status. We divided housing damage into four groups according to the degree of damage to the house; total loss $(\geq 50 \%)$, half loss $(\geq 20 \%$ but $<50 \%)$, partial loss $(\geq 3 \%$ but $<20 \%)$ and no damage.

We evaluated the disease activity for two consecutive months before and two consecutive months after the Great East Japan Earthquake using the Mayo score for $\mathrm{UC}^{18}$ or Harvey-Bradshaw index for $\mathrm{CD},{ }^{19}$ depending on which was available in the hospital records and questionnaires. The Mayo score is comprised of information on stool frequency, rectal bleeding, findings on endoscopy and a physician's global assessment. Scores can range from 0 to 12 . However, we used an abridged Mayo score (range from 0 to 9) that excluded findings on endoscopy because routine endoscopic examinations were not performed so soon after the earthquake. The Harvey-Bradshaw index is comprised of information on general condition, abdominal pain, diarrhoea frequency, abdominal mass and complications. Higher scores for both the Mayo score and the Harvey-Bradshaw index indicate more severe disease activity. IBD patients having a stoma were excluded because of difficulties in counting bowel movements.

In this study, 'active' was defined as follows: a partial Mayo score $=2$ or more $(\mathrm{UC})$ and a Harvey-Bradshaw index $=6$ or more $(\mathrm{CD})$. Lower scores indicated inactive disease. We defined 'relapse' as a change from inactive to active and 'remission' as a change from active to inactive across 2 months before and 2 months after the earthquake. The patients who remained active or inactive during the study period were considered to have 'stable disease'. We compared the relapse and remission rates with those during the corresponding period in the previous year as controls.

\section{Statistical analysis}

Quantitative data are presented as mean \pm SD. Discrete variables are presented as median and range. All statistical analyses were performed using the JMP V.9 (SAS Institute Inc, Cary, North Carolina, USA). Differences between two groups were evaluated using $\chi^{2}$ test or Fisher's exact probability test, unpaired t test or Wilcoxon signed-rank test, as appropriate. A multiple logistic regression method that included all possible variables was used. The level of statistical significance was set at $\mathrm{p}<0.05$.

\section{RESULTS}

\section{Patients' clinical characteristics}

A total of 903 completed questionnaires (from 546 UC and $357 \mathrm{CD}$ ) were returned to us. The response rate to the questionnaire was $83.6 \%(903 / 1080)$. We examined 
the hospital records for each patient. Of the UC patients, $269(49.3 \%)$ were men and $277(50.7 \%)$ were women. The mean age was $45.3 \pm 16.6$ years and the mean disease duration was $9.7 \pm 9.0$ years. The extent of disease was as follows: 208 patients $(38.1 \%)$, total colitis (over splenic flexure); 183 (33.5\%), left-sided colitis (up to splenic flexure); and 83 (15.2\%), proctitis (up to the rectum). The extent was unknown in 72 patients (13.2\%). Among the CD patients, there were 253 men $(70.9 \%)$ and 104 women $(29.1 \%)$. The mean age was $37.1 \pm 12.5$ years and the mean disease duration was 11.6 \pm 8.1 years. The location of disease was as follows: 61 patients $(17.1 \%)$, small intestine; $47(13.2 \%)$, colon and $212(59.4 \%)$, both small intestine and colon. The location was unknown in 37 patients $(10.3 \%)$ (table 1$)$.

Fifty-one UC (9.3\%) and 43 CD (12.0\%) patients experienced extraintestinal complications. Of the UC patients, $55(10.1 \%)$ were current smokers and 162 $(29.7 \%)$ were past smokers. On the other hand, $85 \mathrm{CD}$ patients $(23.8 \%)$ were current smokers and $74(20.7 \%)$ were past smokers. Of the 277 females with UC, 181 $(65.3 \%)$ had experienced pregnancy, while only 41 of $104 \mathrm{CD}$ females $(39.4 \%)$ had experienced pregnancy. Five UC patients and three CD patients were pregnant when the earthquake occurred (table 1). Medications used by the IBD patients before the earthquake are shown in table 2.
Deleterious effects of the earthquake

Of the 903 IBD patients, the houses of 501 patients $(55.5 \%)$ were damaged; partial loss was experienced by 369 patients $(40.9 \%)$, half loss by 58 patients $(6.4 \%)$ and total loss by 74 patients $(8.2 \%)$. As a result, 62 $(6.9 \%)$ patients had to stay in refuge facilities for 1 week or more. A total of 175 patients (19.4\%) experienced the death of a family member or a friend (table 3 ).

Only 51 patients $(5.7 \%)$ experienced complete loss of their jobs after the earthquake. However, $279(30.9 \%)$ and $157(17.4 \%)$ patients, respectively, reported short-term (for the next several months) and long-term (for the next several years) anxiety about their family finances (table 3 ).

Because of temporary homelessness and difficulty in obtaining various types of food, changes in daily intake such as fat, vegetables, fruits, etc were experienced by 269 patients $(29.8 \%)$ after the earthquake. With regard to medications, 69 patients $(11.7 \%)$ interrupted medications for a week or more because they had lost their medicines or could not consult with doctors (table 3).

\section{Changes in disease activity before and after the earthquake}

Of the UC patients, disease was active in 167 patients $(30.6 \%)$ and inactive in 379 patients $(69.4 \%)$ before the earthquake. After the earthquake, the activity scores increased significantly $(p<0.0001)$. A total of 86 patients

Table 1 Patients' clinical characteristics

\begin{tabular}{|c|c|c|c|}
\hline & Ulcerative colitis & Crohn's disease & Total \\
\hline Number of patients & 546 & 357 & 903 \\
\hline \multicolumn{4}{|l|}{ Gender } \\
\hline Male & $269(49.3 \%)$ & $253(70.9 \%)$ & $522(57.8 \%)$ \\
\hline Female & $277(50.7 \%)$ & $104(29.1 \%)$ & $381(42.2 \%)$ \\
\hline Age (years) & $45.3 \pm 16.6$ & $37.1 \pm 12.5$ & $42.0 \pm 15.6$ \\
\hline Disease duration (years) & $9.7 \pm 9.0$ & $11.6 \pm 8.1$ & $10.5 \pm 8.7$ \\
\hline \multicolumn{4}{|l|}{ Disease extent } \\
\hline Total colitis & $208(38.1 \%)$ & - & \\
\hline Left-sided colitis & $183(33.5 \%)$ & - & \\
\hline Proctitis & $83(15.2 \%)$ & - & \\
\hline Unknown & $72(13.2 \%)$ & - & \\
\hline \multicolumn{4}{|l|}{ Disease location } \\
\hline Small intestine & - & $61(17.1 \%)$ & \\
\hline Colon & - & $212(59.4 \%)$ & \\
\hline Small intestine and colon & - & $47(13.2 \%)$ & \\
\hline Unknown & - & $37(10.3 \%)$ & \\
\hline \multicolumn{4}{|l|}{ Extra-intestinal complications } \\
\hline Positive & $51(9.3 \%)$ & $43(12.0 \%)$ & $94(10.4 \%)$ \\
\hline None & $495(90.7 \%)$ & $314(88.0 \%)$ & $809(89.6 \%)$ \\
\hline \multicolumn{4}{|l|}{ Smoking status } \\
\hline Current smokers & $55(10.1 \%)$ & $85(23.8 \%)$ & $140(15.5 \%)$ \\
\hline Past smokers & $162(29.7 \%)$ & $74(20.7 \%)$ & $236(26.1 \%)$ \\
\hline None & 327 (59.9\%) & $198(55.5 \%)$ & $525(58.2 \%)$ \\
\hline Unclear & $2(0.3 \%)$ & $0(0.0 \%)$ & $2(0.2 \%)$ \\
\hline \multicolumn{4}{|l|}{ Pregnancy experience } \\
\hline $\begin{array}{l}\text { Positive } \\
\text { (During the earthquake) }\end{array}$ & $\begin{array}{l}181 / 277 \\
(5)\end{array}$ & $\begin{array}{l}41 / 104 \\
(3)\end{array}$ & $\begin{array}{l}222 / 381 \\
(8)\end{array}$ \\
\hline
\end{tabular}


Table 2 Use of medications before the Great East Japan Earthquake

\begin{tabular}{llll}
\hline & Ulcerative colitis (N=546) & Crohn's disease (N=357) & Total (N=903) \\
\hline 5-ASA or SASP & $486(89.0 \%)$ & $276(77.3 \%)$ & $762(84.4 \%)$ \\
PSL & $79(9.0 \%)$ & $26(7.3 \%)$ & $105(11.6 \%)$ \\
$(\mathrm{mg})$ & $(1-60)$ & $(1-40)$ & $111(12.3 \%)$ \\
AZA or 6-MP & $56(10.3 \%)$ & $55(15.4 \%)$ & $4(0.4 \%)$ \\
$(\mathrm{mg})$ & $(15-100)$ & $(10-100)$ & $169(1807 \%)$ \\
Tacrolimus & $4(0.7 \%)$ & - & $151(42.3 \%)$ \\
IFX & $18(3.3 \%)$ & $(150-500)$ & $11(1.2 \%)$ \\
(mg) & $(200-500)$ & $11(3.1 \%)$ & $3(0.3 \%)$ \\
ADA & - & $3(0.8 \%)$ & $70(7.8 \%)$ \\
TPN & $0(0.0 \%)$ & $70(19.6 \%)$ & $(300-1,800)$ \\
ED & & $1(0.3 \%)$ & $4(0.4 \%)$ \\
(kcal/day) & $3(0.5 \%)$ & & \\
CAP & & & \\
\hline 5-ASA, aminosalicilic acid; ADA, adalimumab; AZA, azathioprine; CAP, cytoapheresis; ED, elemental diet; IFX, infliximab; MP, \\
mercaptopurine; PSL, prednisolone; SASP, salazosurufapirizine; TPN, total parenteral nutrition.
\end{tabular}

relapsed and the disease status became inactive in 22 patients; therefore, the relapse rate (from inactive to active) was $15.8 \%(86 / 546)$ and the remission rate (from active to inactive) was $4 \%(22 / 546)$. The relapse rate was significantly higher than in the previous year (8.8\%, data not shown). On the other hand, the remission rate was significantly lower than in the previous year (8.8\%, data not shown).

Of the CD patients, 86 patients $(24.1 \%)$ had active disease and 271 patients $(75.9 \%)$ had inactive disease before the earthquake. After the earthquake, the activity indices had hardly changed. A total of 25 patients relapsed and the disease status became inactive in 16 patients; therefore, the relapse rate (from inactive to active) was $7 \%(25 / 357)$ and the remission rate (from active to inactive) was $4.5 \%(16 / 357)$. Unlike UC, the relapse rate among $\mathrm{CD}$ patients was slightly, but not significantly, higher than in the previous year $(5.3 \%$, data not shown). On the other hand, the remission rate was twice that of the previous year (2.2\%, data not shown), but did not differ significantly.

Because of relapses, 96 patients (10.6\%) required additional medication after the earthquake as follows: prednisolone (27 patients), tacrolimus (3), azathioprine (11), infliximab (13), adalimumab (6), total parenteral nutrition (4) or others.

\section{Possible variables for relapse or remission}

There were no differences in the patients' clinical characteristics between the relapse group and non-relapse group. With regard to remission, there were also no differences in the patients' clinical characteristics between the remission group and non-remission group.

Multivariate analyses revealed that $\mathrm{UC}$, changes in oral intake and anxiety about family finances were independent predictors of relapse with an adjusted OR of 2.86 (95\% CI 1.73 to 4.87$), 1.83$ (1.16 to 2.88 ) and 1.69 (1.05 to 2.70 ), respectively (table 4 ). On the other hand, no factor was identified as an independent predictor of remission (table 5).

\section{DISCUSSION}

Of the 903 IBD patients, 132 patients (14.6\%) had experienced damage to their homes of half or more and 175 patients $(19.4 \%)$ had experienced the death of a family member or friend. These factors would suggest that the Great East Japan Earthquake was very likely one of the most stressful life events for those affected. The response rate to the questionnaire $(83.6 \%)$ was satisfactory. However, the damage caused by the earthquake might have been more serious, because the nonresponse group might have included patients who had taken refuge somewhere or died. The present study showed that life-event stress induced by the Great East Japan Earthquake was associated with relapse of UC but not CD. This is the first report that investigated the activities of a large number of IBD patients before and after a huge earthquake.

As for the patient's clinical characteristics, gender, age, IBD duration, extraintestinal complications and smoking status did not influence the incidence of relapses, with the exception of IBD type (UC or CD). As aforementioned, there have been many reports that psychological stress may induce flares of UC. ${ }^{1-8}$ On the other hand, there have been few reports about relapses of CD. ${ }^{48}$ Our present study demonstrated that psychological stress was associated with relapse in UC but not CD. In terms of damage and other deleterious effects from the earthquake, damage to houses, duration of temporary homelessness, death of family members or friends and unemployment were not associated with relapses of IBD; however, anxiety about family finances was related to relapse. These results may suggest that psychological stress or uneasiness about the future has a greater effect on UC relapses than direct damage and losses. 
Table 3 Damage and deleterious effects of the Great East Japan Earthquake

\begin{tabular}{|c|c|c|c|}
\hline & Ulcerative colitis $(\mathrm{N}=546)$ & Crohn's disease (N=357) & Total $(\mathrm{N}=903)$ \\
\hline \multicolumn{4}{|l|}{ Damage to houses } \\
\hline Total loss ( $\geq 50 \%)$ & $36(6.6 \%)$ & $38(10.6 \%)$ & $74(8.2 \%)$ \\
\hline Half-loss ( $\geq 20 \%$ but $<50 \%$ ) & $37(6.8 \%)$ & $21(5.9 \%)$ & $58(6.4 \%)$ \\
\hline Partial loss ( $\geq 3 \%$ but $<20 \%$ ) & $236(43.2 \%)$ & $133(37.3 \%)$ & $369(40.9 \%)$ \\
\hline None & $233(42.7 \%)$ & $161(45.1 \%)$ & 394 (43.6\%) \\
\hline Unclear & $4(0.7 \%)$ & $4(1.1 \%)$ & $8(0.9 \%)$ \\
\hline \multicolumn{4}{|l|}{ Temporary homelessness } \\
\hline 1 week or more & $37(6.8 \%)$ & $25(7.0 \%)$ & $62(6.9 \%)$ \\
\hline Less than 1 week or none & $503(92.1 \%)$ & $331(92.7 \%)$ & $834(92.3 \%)$ \\
\hline Unclear & $6(1.1 \%)$ & $1(0.3 \%)$ & $7(0.8 \%)$ \\
\hline \multicolumn{4}{|l|}{ Death of family members or friends } \\
\hline Yes & $106(19.4 \%)$ & $69(19.3 \%)$ & $175(19.4 \%)$ \\
\hline None & $435(79.7 \%)$ & $284(79.6 \%)$ & $719(79.6 \%)$ \\
\hline Unclear & $5(0.9 \%)$ & $4(1.1 \%)$ & $9(1.0 \%)$ \\
\hline \multicolumn{4}{|l|}{ Changes in daily dietary intake } \\
\hline Yes & $153(28.0 \%)$ & $116(32.5 \%)$ & 269 (29.8\%) \\
\hline No & $387(70.9 \%)$ & $239(66.9 \%)$ & $626(69.3 \%)$ \\
\hline Unclear & $6(1.1 \%)$ & $2(0.6 \%)$ & $8(0.9 \%)$ \\
\hline \multicolumn{4}{|l|}{ Discontinuation of medications } \\
\hline 1 week or more & $39(9.8 \%)$ & $30(14.1 \%)$ & $69(11.7 \%)$ \\
\hline None & $507(9.8 \%)$ & $327(14.1 \%)$ & $834(11.7 \%)$ \\
\hline Unclear & $358(90.2 \%)$ & $256(85.9 \%)$ & $614(88.3 \%)$ \\
\hline \multicolumn{4}{|l|}{ Interruption in IFX or ADA } \\
\hline Yes & $1 / 18$ & 19/162 & $20 / 180$ \\
\hline \multicolumn{4}{|l|}{ Complete loss of job } \\
\hline Yes & $26(4.8 \%)$ & $25(7.0 \%)$ & $51(5.7 \%)$ \\
\hline None & $518(94.9 \%)$ & $330(92.4 \%)$ & $848(93.9 \%)$ \\
\hline Unclear & $2(0.3 \%)$ & $2(5.6 \%)$ & $4(0.4 \%)$ \\
\hline \multicolumn{4}{|l|}{ Anxiety about family finances } \\
\hline Yes & $167(30.6 \%)$ & $145(40.6 \%)$ & $312(34.6 \%)$ \\
\hline (Short-term anxiety) & $(147)$ & $(132)$ & $(279)$ \\
\hline (Long-term anxiety) & (83) & $(74)$ & (157) \\
\hline None & $376(68.9 \%)$ & $211(59.1 \%)$ & $587(65.0 \%)$ \\
\hline Unclear & $3(0.5 \%)$ & $1(0.3 \%)$ & $4(0.4 \%)$ \\
\hline \multicolumn{4}{|l|}{ Changes in smoking status } \\
\hline Stopped after the earthquake & 9 & 5 & 14 \\
\hline Restarted after the earthquake & 10 & 5 & 15 \\
\hline
\end{tabular}

Although the discontinuation of medication had no influence on relapses of IBD, changes in daily dietary intake did. A relationship between dietary factors and the onset or relapses of IBD has been reported. ${ }^{20-22}$ After the earthquake, many patients could not obtain enough fresh food; therefore, they consumed more processed foods and fewer fresh vegetables and fruits. With regard to the possible variables related to remission, we expected that a decrease in the total volume or in fatty foods would be associated with remission, especially in CD patients. However, our results did not support this hypothesis. This might have been the result of the period of dietary restriction being not so long. There were few patients that changed their smoking status after the earthquake; therefore, we could not include this factor in multivariate analyses. However, changes in smoking status may have been an important factor in relapses of UC but not $\mathrm{CD}$. Of the nine UC patients who stopped smoking after the earthquake, seven experienced relapses $(p=0.002)$. Beaugerie et $a l^{23}$ reported that among smokers with UC who stopped smoking, the disease severity increased after cessation. Over the short term, smoking itself did not appear to influence relapse or remission; however, changes in smoking status were associated with a relapse in UC.

Our study had some limitations. First, we did not use validated scores that could objectively assess psychological stress such as the Cohen Perceived Stress Scale. ${ }^{24}$ Since huge earthquakes usually happen without warning, it is impossible to investigate stress several times before and after an earthquake. Therefore, we assessed the degree of stress by examining information about 
Table 4 Possible variables for relapse after the Great East Japan Earthquake

\begin{tabular}{|c|c|c|c|c|}
\hline & & OR & p Value & $95 \% \mathrm{Cl}$ \\
\hline \multicolumn{5}{|l|}{ IBD type } \\
\hline Ulcerative colitis & 546 & 2.86 & $<0.0001$ & 1.73 to 4.87 \\
\hline Crohn's disease & 357 & 1 & & \\
\hline \multicolumn{5}{|l|}{ Gender } \\
\hline Male & 522 & 0.78 & 0.26 & 0.50 to 1.20 \\
\hline Female & 381 & 1 & & \\
\hline \multicolumn{5}{|l|}{$\mathrm{Age}^{\star}$} \\
\hline More than 40 years & 423 & 0.72 & 0.16 & 0.45 to 1.14 \\
\hline 40 or less & 479 & 1 & & \\
\hline \multicolumn{5}{|l|}{ Disease duration } \\
\hline More than 10 years & 350 & 0.94 & 0.80 & 0.58 to 1.50 \\
\hline 10 or less & 553 & 1 & & \\
\hline \multicolumn{5}{|c|}{ Extra-intestinal complications } \\
\hline Positive & 94 & 1.40 & 0.32 & 0.71 to 2.59 \\
\hline None & 809 & 1 & & \\
\hline \multicolumn{5}{|l|}{ Smoking status* } \\
\hline Current smokers & 140 & 0.95 & 0.88 & 0.48 to 1.76 \\
\hline Others & 761 & 1 & & \\
\hline \multicolumn{5}{|l|}{ Damage to houses* } \\
\hline Total or half loss & 132 & 1.01 & 0.97 & 0.52 to 1.88 \\
\hline Others & 763 & 1 & & \\
\hline \multicolumn{5}{|c|}{ Temporary homelessness* } \\
\hline 1 week or more & 62 & 0.97 & 0.94 & 0.41 to 2.14 \\
\hline Others & 834 & 1 & & \\
\hline \multicolumn{5}{|c|}{ Death of family members or friends* } \\
\hline Yes & 175 & 1.20 & 0.50 & 0.70 to 2.03 \\
\hline None & 719 & 1 & & \\
\hline \multicolumn{5}{|l|}{ Complete loss of job* } \\
\hline Yes & 51 & 1.55 & 0.31 & 0.65 to 3.47 \\
\hline None & 848 & 1 & & \\
\hline \multicolumn{5}{|c|}{ Anxiety about family finances* } \\
\hline Yes & 312 & 1.69 & 0.03 & 1.05 to 2.70 \\
\hline None & 587 & 1 & & \\
\hline \multicolumn{5}{|c|}{ Changes in daily dietary intake* } \\
\hline Yes & 269 & 1.83 & $<0.01$ & 1.16 to 2.88 \\
\hline None & 626 & 1 & & \\
\hline \multicolumn{5}{|c|}{ Discontinuation of medications } \\
\hline 1 week or more & 69 & 1.49 & 0.30 & 0.69 to 2.98 \\
\hline None & 834 & 1 & & \\
\hline
\end{tabular}

*Information on several patients about age, smoking status, damage to houses, temporary homelessness, death of family members or friends, complete loss of job, anxiety about family finances and changes in daily dietary intake was not available.

$\mathrm{IBD}$, inflammatory bowel disease.

damage and changes in lifestyle after the Great East Japan Earthquake. Second, our study cannot exclude recall bias. It was difficult to administer a questionnaire immediately after the earthquake, which is why we obtained data about clinical characteristics and activities from both questionnaires and medical records. Third, non-steroidal anti-inflammatory drugs (NSAIDs) and antibiotics may contribute to relapses of IBD.$^{25}$ However, we think the numbers of newly prescribed NSAIDs and antibiotics during the study period were less than, or equal to, those of the corresponding period in the previous year. Because of the difficulty in obtaining medicine after an earthquake, the numbers of newly prescribed
NSAIDs and antibiotics might have decreased. In addition, unlike in the case of UC patients, twice as many men as women were $\mathrm{CD}$ patients, which is in agreement with previous reports in Japan. ${ }^{26-28}$ More CD patients were current smokers than those with UC, in agreement with previous reports. ${ }^{8} 20$

Life-event stress induced by the Great East Japan Earthquake was related to relapses in UC but not CD. We hope that this report will be useful to the management of patients with IBD, not only during catastrophic events but also generally. For the future, a prospective study should be undertaken to determine whether stress is actually related to relapses of IBD. 
Table 5 Possible variables for remission after the Great East Japan Earthquake

\begin{tabular}{|c|c|c|c|c|}
\hline & & OR & p Value & $95 \% \mathrm{Cl}$ \\
\hline \multicolumn{5}{|l|}{ IBD type } \\
\hline Ulcerative colitis & 546 & 0.81 & 0.58 & 0.39 to 1.72 \\
\hline Crohn's disease & 357 & 1 & & \\
\hline \multicolumn{5}{|l|}{ Gender } \\
\hline Male & 522 & 0.84 & 0.62 & 0.41 to 1.72 \\
\hline Female & 381 & 1 & & \\
\hline \multicolumn{5}{|l|}{$\mathrm{Age}^{\star}$} \\
\hline More than 40 years & 423 & 0.89 & 0.76 & 0.41 to 1.88 \\
\hline 40 years or less & 479 & 1 & & \\
\hline \multicolumn{5}{|l|}{ Disease duration } \\
\hline More than 10 years & 350 & 0.63 & 0.25 & 0.27 to 1.37 \\
\hline 10 or less & 553 & 1 & & \\
\hline \multicolumn{5}{|c|}{ Extra-intestinal complications } \\
\hline Positive & 94 & 0.80 & 0.71 & 0.19 to 2.33 \\
\hline None & 809 & 1 & & \\
\hline \multicolumn{5}{|l|}{ Smoking status* } \\
\hline Current smokers & 140 & 0.70 & 0.52 & 0.20 to 1.90 \\
\hline Others & 761 & 1 & & \\
\hline \multicolumn{5}{|l|}{ Damage to houses* } \\
\hline Total or half loss & 132 & 1.07 & 0.90 & 0.33 to 2.86 \\
\hline Others & 763 & 1 & & \\
\hline \multicolumn{5}{|c|}{ Temporary homelessness* } \\
\hline 1 week or more & 62 & 0.82 & 0.81 & 0.12 to 3.40 \\
\hline Others & 834 & 1 & & \\
\hline \multicolumn{5}{|c|}{ Death of family members or friends* } \\
\hline Yes & 175 & 0.58 & 0.28 & 0.18 to 1.51 \\
\hline None & 719 & 1 & & \\
\hline \multicolumn{5}{|l|}{ Complete loss of job* } \\
\hline Yes & 51 & 2.23 & 0.28 & 0.47 to 7.87 \\
\hline None & 848 & 1 & & \\
\hline \multicolumn{5}{|c|}{ Anxiety about family finances* } \\
\hline Yes & 312 & 1.06 & 0.89 & 0.47 to 2.26 \\
\hline None & 587 & 1 & & \\
\hline \multicolumn{5}{|c|}{ Changes in daily dietary intake* } \\
\hline Yes & 269 & 1.26 & 0.55 & 0.58 to 2.62 \\
\hline None & 626 & 1 & & \\
\hline \multicolumn{5}{|c|}{ Discontinuation of medications } \\
\hline 1 week or more & 69 & 0.36 & 0.26 & 0.02 to 1.80 \\
\hline None & 834 & 1 & & \\
\hline
\end{tabular}

*Information on several patients about age, smoking status, damage to houses, temporary homelessness, death of family members or friends, complete loss of job, anxiety about family finances, and changes in daily dietary intake was not available.

$\mathrm{IBD}$, inflammatory bowel disease.

\section{Author affiliations}

${ }^{1}$ Division of Gastroenterology, Tohoku University Graduate School of Medicine, Sendai, Japan

${ }^{2}$ Department of Gastroenterology, Japanese Red Cross Ishinomaki Hospital, Ishinomaki, Japan

${ }^{3}$ Department of Gastroenterology, Sendai Medical Center, Sendai, Japan

${ }^{4}$ Takagi Clinic, Sendai, Japan

${ }^{5}$ Department of Gastroenterology, Osaki Citizen Hospital, Osaki, Japan

${ }^{6}$ Department of Gastroenterology, Sendai City Hospital, Sendai, Japan

${ }^{7}$ Department of Gastroenterology, Japanese Red Cross Sendai Hospital, Sendai, Japan

${ }^{8}$ Department of Gastroenterology, Miyagi Cancer Center, Natori, Japan ${ }^{9}$ Department of Gastroenterology, Iwate Prefectural Isawa Hospital, Oshu, Japan

${ }^{10}$ Department of Gastroenterology, Iwate Prefectural Chubu Hospital, Kitakami, Japan
${ }^{11}$ Department of Gastroenterology, South Miyagi Medical Center, Ogawara Japan

${ }^{12}$ Department of Gastroenterology, Iwate Prefectural Iwai Hospital, Ichinoseki, Japan

${ }^{13}$ Department of Internal Medicine, Kesennuma City Hospital, Kesennuma, Japan

Acknowledgements We received two rounds of language review from medical editors.

Contributor HS and TM had the original idea for this study and were involved in writing the original study protocol, data collection and writing of the manuscript. GT, HT, ShoT, NO, TK, SO, EN, MS, YS, ShT, KU, HY, KE, YK, $\mathrm{HA}, \mathrm{MM}$, TKand MK were involved in data collection and contributed to discussions. YK, SeT and TS contributed to discussions and reviewed the 
manuscript. All authors had full access to all of the data in this study and can take responsibility for the integrity of the data and the accuracy of the data analysis.

Funding This research received no specific grant from any funding agency in the public, commercial or not-for-profit sectors.

Competing interests None.

Ethics approval This study was approved by the Tohoku University Hospital Committee for Clinical Investigation.

Patient consent Obtained.

Provenance and peer review Not commissioned; externally peer reviewed.

Data sharing statement There are no additional data available.

\section{REFERENCES}

1. Mawdsley JE, Rampton DS. Psychological stress in IBD: new insights into pathogenic and therapeutic implications. Gut 2005;54:1481-91.

2. Levenstein S, Prantera C, Varvo V, et al. Stress and exacerbation in ulcerative colitis: a prospective study of patients enrolled in remission. Am J Gastroenterol 2000;95:1213-20.

3. Bitton A, Sewitch MJ, Peppercorn MA, et al. Psychosocial determinants of relapse in ulcerative colitis: a longitudinal study. Am J Gastroenterol 2003;98:2203-8.

4. Mittermaier C, Dejaco C, Waldhoer T, et al. Impact of depressive mood on relapse in patients with inflammatory bowel disease: a prospective 18-month follow-up study. Psychosom Med 2004;66:79-84.

5. Mawdsley JE, Macey MG, Feakins RM, et al. The effect of acute psychologic stress on systemic and rectal mucosal measures of inflammation in ulcerative colitis. Gastroenterology 2006;131:410-19.

6. Maunder RG, Greenberg GR, Nolan RP, et al. Autonomic response to standardized stress predicts subsequent disease activity in ulcerative colitis. Eur J Gastroenterol Hepatol 2006;18:413-20.

7. Bitton A, Dobkin P, Edwardes MD, et al. Predicting relapse in Crohn's disease: a biopsychosocial model. Gut 2008;57:1386-92.

8. Bernstein CN, Singh S, Graff LA, et al. A prospective population-based study of triggers of symptomatic flares in IBD. Am J Gastroenterol 2010;105:1994-2002.

9. North CS, Alpers DH, Helzer JE, et al. Do life events or depression exacerbate inflammatory bowel disease? A prospective study. Ann Intern Med 1991;114:381-6.

10. Vidal A, Gomez-Gil E, Sans M, et al. Life events and inflammatory bowel disease relapse: a prospective study of patients enrolled in remission. Am J Gastroenterol 2006;101:775-81.

11. Mikocka-Walus AA, Turnbull DA, Moulding NT, et al. Does psychological status influence clinical outcomes in patients with inflammatory bowel disease (IBD) and other chronic gastroenterological diseases: an observational cohort prospective study. Biopsychosoc Med 2008;2:11-19.

12. Takakura R, Himeno S, Kanayama $\mathrm{Y}$, et al. Follow-up after the Hanshin-Awaji earthquake: diverse influences on pneumonia, bronchial asthma, peptic ulcer and diabetes mellitus. Intern Med 1997;36:87-91.

13. Matsuoka T, Yoshioka T, Oda J, et al. The impact of a catastrophic earthquake on morbidity rates for various illnesses. Public Health 2000;114:249-53.

14. Aoyama N, Kinoshita Y, Fujimoto S, et al. Peptic ulcers after the Hanshin-Awaji earthquake: increased incidence of bleeding gastric ulcers. Am J Gastroenterol 1998;93:311-16.

15. Aoki T, Fukumoto Y, Yasuda S, et al. The Great East Japan Earthquake Disaster and cardiovascular diseases. Eur Heart $J$ 2012;33:2796-803

16. Ogawa S, Ishiki M, Nako K, et al. Effects of the Great East Japan Earthquake and huge tsunami on glycaemic control and blood pressure in patients with diabetes mellitus. BMJ Open 2012;2: e000830.

17. Aoyagi $\mathrm{T}$, Yamada $\mathrm{M}$, Kunishima $\mathrm{H}$, et al. Characteristics of infectious diseases in hospitalized patients during the early phase after the 2011 Great East Japan earthquake: pneumonia as a significant reason for hospital care. Chest 2012 (Epub ahead of print).

18. Schroeder KW, Tremaine WJ, Ilstrup DM. Coated oral 5-aminosalicylic acid therapy for mildly to moderately active ulcerative colitis. A randomized study. $N$ Engl J Med 1987;317:1625-9.

19. Harvey RF, Bradshaw JM. A simple index of Crohn's-disease activity. Lancet 1980;1:514.

20. Thornton JR, Emmett PM, Heaton KW. Smoking, sugar, and inflammatory bowel disease. Br Med J 1985;290:1786-7.

21. Jowett SL, Seal CJ, Pearce MS, et al. Influence of dietary factors on the clinical course of ulcerative colitis: a prospective cohort study. Gut 2004;53:1479-84

22. Jantchou $\mathrm{P}$, Morois S, Clavel-Chapelon F, et al. Animal protein intake and risk of inflammatory bowel disease: the E3N prospective study. Am J Gastroenterol 2010;105:2195-201.

23. Beaugerie L, Massot N, Carbonnel F, et al. Impact of cessation of smoking on the course of ulcerative colitis. Am J Gastroenterol 2001;96:2113-16

24. Cohen S, Kamarck T, Mermelstein R. A global measure of perceived stress. J Health Soc Behav 1983:24:385-96.

25. Singh S, Graff LA, Bernstein CN. Do NSAIDs, antibiotics, infections, or stress trigger flares in IBD? Am J Gastroenterol 2009:104:1298-313.

26. Yao T, Matsui T, Hiwatashi N. Crohn's disease in Japan: diagnostic criteria and epidemiology. Dis Colon Rectum 2000;43:S85-93.

27. Asakura $\mathrm{K}$, Nishiwaki $\mathrm{Y}$, Inoue $\mathrm{N}$, et al. Prevalence of ulcerative colitis and Crohn's disease in Japan. J Gastroenterol 2009;44:659-65.

28. Ishige T, Tomomasa T, Takebayashi T, et al. Inflammatory bowel disease in children: epidemiological analysis of the nationwide IBD registry in Japan. J Gastroenterol 2010;45:911-17. 